\title{
OS DESAFIOS DA INCLUSÃO DIGITAL NOS ESPAÇOS ACADÊMICOS: ENSINO A DISTÂNCIA EM TEMPOS DE PANDEMIA, UM LABORATÓRIO PARA A EDUCAÇÃO
}

\author{
THE CHALLENGES OF DIGITAL INCLUSION IN ACADEMIC SPACES: \\ DISTANCE LEARNING IN TIMES OF PANDEMIC, A LABORATORY FOR \\ EDUCATION
}

\author{
Kátia Luciene de Oliveira e Silva Santana ${ }^{22}$ \\ Scheyla Taveira da Silva ${ }^{23}$
}

\begin{abstract}
Resumo
O presente artigo busca analisar o tema do ensino remoto emergencial implementado no Brasil, enquanto estratégia de política pública de prevenção do contágio e combate à propagação do novo coronavírus (COVID-19). Nesse sentido, as experiências vividas por nós - duas professoras de História - no cotidiano da prática de tutoria no ensino superior e da docência no ensino médio (rede estadual) e superior (rede particular) são o eixo norteador desta discussão. As reflexões sobre o uso dessa modalidade nos espaços acadêmicos, na conjuntura atual, como instrumento de ensino-aprendizagem, pressupõem um olhar voltado para os desafios que envolvem a inclusão digital, considerando as especificidades pedagógicas, humanas e regionais. Assim sendo, partindo de relatos de experiências, foi possível perceber as complexas e aceleradas adequações às quais os docentes estão submetidos nesse contexto pandêmico. Acreditamos que é no campo do vivido que o sujeito ressignifica os desafios cotidianos e desenvolve consciência do seu papel no mundo.
\end{abstract}

Palavras-chave: Autonomia. Ensino a distância (EAD). Ensino remoto emergencial. Experiência.

\begin{abstract}
This article aims at analyzing the theme of emergency remote learning implemented in Brazil, as a strategy of public politics to prevent the contagion and in the combat to the new coronavirus propagation, (COVID-19). In this sense, the experiences lived by us two history teachers - in the daily practice of mentoring in higher education and

\footnotetext{
${ }^{22}$ Mestre em história pela Universidade Federal Rural do Rio de Janeiro (PPHR/UFRRJ) e doutoranda pela mesma instituição. Professora do curso de licenciatura em História e tutora da rede privada de ensino. Email: kalucih@gmail.com . Orcid: https://orcid.org/0000-0002-5707-9931.

${ }^{23}$ Doutoranda em História pela Universidade Federal Rural do Rio de Janeiro (PPHR/UFRRJ). Professora Docente I da SEEDUC/RJ. Professora do curso de licenciatura em História da rede privada de ensino. Email: scheylat@hotmail.com. Orcid: https://orcid.org/0000-0002-8878-9063.
} 


\section{RevistAleph}

teaching in the high school (state educational system) and in higher education (private network) are the guidelines of this discussion. The thoughts about the use of this modality in academic spaces in nowadays scenario as instrument of teaching-learning imply a look to the challenges that involve digital inclusion, considering the pedagogical, human, and regional particularities. Therefore, starting from the approach of an experience report, it was possible to notice the complex and fast adequations the teachers are subject to in this pandemic context. We believe that it is in the field of the experience that the subject re-signifies the daily challenges and develops consciousness of his/her role in the world.

Keywords: Autonomy. Distance learning (EAD). Emergency remote education. Experience.

\section{Introdução}

No contexto atual de saúde pública no Brasil, o relato de experiências na área da Educação pressupõe um momento para reflexão sobre um dos segmentos profissionais mais afetados pela pandemia: a docência. No decorrer deste artigo, abordaremos a atuação desses profissionais e das práticas docentes no modelo emergencial e virtual de ensino, no intuito de compartilhar certas ações e percepções que possam contribuir para os estudos sobre essa singular experiência na área da Educação no século XXI. Para tanto, partimos da exposição de algumas histórias vivenciadas por nós duas ${ }^{24}$, professoras de História e tutoras, em duas instituições da rede privada de ensino superior, localizadas, respectivamente, na Zona Oeste da cidade do Rio de Janeiro e na Baixada Fluminense, durante o primeiro semestre do ano de 2020. Também será objeto de análise e discussão, a atuação em uma escola da rede estadual de educação do Rio de Janeiro, na Baixada Fluminense.

Guardadas as diferenças de formação e atuação entre tutores e professores, são

\footnotetext{
${ }^{24}$ Kátia Luciene de Oliveira e Silva Santana é tutora das disciplinas do eixo de formação a distância dos cursos de graduação presencial, e professora do curso de graduação em História, atuando em duas instituições de ensino superior da rede privada. Scheyla Taveira da Silva é professora do curso de graduação em História, em instituição de ensino superior da rede privada, e professora docente I da SEEDUC/RJ, atuando nas turmas de ensino médio, na região da Baixada Fluminense.
} 


\section{RevistAleph}

os significados epistemológicos - o estudante como sujeito da educação e sujeito objeto da orientação; a mediação entre o estudante e o cotidiano escolar; a capacidade de identificar a realidade do indivíduo e, assim, facilitar sua interação e comunicação social - que contribuem e se alinham com essas práticas nos espaços acadêmicos. Para tanto, no desempenho da função de professor/tutor/orientador, além de refletir sobre a prática docente, é preciso superar a ideia de ajustar o educando. Deve-se, então, enxergar sua compreensão de mundo, seus valores e sua realidade concreta, pois "a orientação educacional, compromissada com um ensino democrático e com um ensino de qualidade, busca uma ação mais abrangente[...]" (RANGEL, 2011, p. 187).

Na virada do século XXI, esse cenário de debates sobre um ensino democrático e de qualidade ensejou a criação do projeto Universidade Aberta do Brasil (UAB) em 2005. De acordo com Zuin (2006), em linhas gerais, a proposta do Ministério da Educação (MEC) era ampliar o ensino superior e gratuito no país, partindo de um "sistema nacional de educação superior a distância" (www.mec.com.br apud ZUIN, 2006, p. 942). A ideia era viabilizar, "até 2011", a formação de "30\%" dos jovens brasileiros em idade universitária (ZUIN, 2006, p. 943). Nesse ínterim, as críticas sobre a "formação aligeirada e artificial dos indivíduos" (COSTA; LEME, 2014, p. 140) vinculavase às teorias-críticas da educação que enxergavam nessa modalidade um distanciamento na "qualidade do conhecimento" (COSTA; LEME, 2014, p. 137).

A priori, a modalidade da educação a distância estava mais voltada para o universo acadêmico (cursos de graduação e pós-graduação). Entretanto, as mediações a distância já se faziam cada dia mais presentes nas escolas, como a comunicação estabelecida entre instituições de ensino, alunos e responsáveis por meio do Portal Acadêmico. Esse meio digital (o portal) também era utilizado como canal institucional de divulgação de informações gerais. Ocorre que todas as discussões estabelecidas, ao longo das últimas duas décadas, em torno da utilização da modalidade a distância 


\section{RevistAleph}

voltada para a educação básica e o ensino superior estão diante de um novo e inusitado cenário.

No contexto extraordinário da pandemia, as providências para o enfrentamento da situação de emergência de saúde pública no Brasil em razão do novo coronavírus motivaram, em regime emergencial, a adoção de medidas legais referentes à educação. O MEC autorizou, por meio da Portaria no 343, de 17 de março de 2020 (BRASIL, 2020a), a substituição das aulas presenciais por aulas em recursos digitais (meios e tecnologias de informação e comunicação) nas instituições de educação superior integrantes do sistema federal de ensino, enquanto durar a situação de pandemia. O governador do Estado do Rio de Janeiro, pelo Decreto no 46.970, de 13 de março de 2020 (RIO DE JANEIRO, 2020a), suspendeu por 15 (quinze) dias as aulas presenciais, antecipando o recesso escolar. Com a Resolução no 5.839, de 16 de março de 2020 (RIO DE JANEIRO, 2020b), a Secretaria Estadual de Educação do Rio de Janeiro (SEEDUC) regulamentou o Decreto n 46.970, estabelecendo a alteração do calendário escolar para o ano letivo de 2020 , bem como o funcionamento das unidades escolares, diretorias regionais e sede da própria secretaria. Embora a norma tenha regulamentado a antecipação do recesso escolar para o período de 16 a 29 de março, a adequação do calendário escolar do ano de 2020 não foi definida, e o assunto ficou para ser tratado em momento posterior. Acreditamos que a incerteza no âmbito da saúde pública, o desconhecimento do novo coronavírus e a ausência de uma perspectiva de solução para o problema tenha motivado o adiamento das decisões em torno do calendário escolar. A suspensão das aulas tem sido prorrogada por decisões efetivadas periodicamente. Contudo, em 1으 de abril do corrente ano, o governo federal, por meio da Medida Provisória no 934 (BRASIL, 2020b), resolveu dispensar os estabelecimentos de ensino de educação básica da obrigatoriedade de observância ao mínimo de dias de efetivo trabalho escolar, bem como as instituições de educação superior da obrigatoriedade de observância ao mínimo de dias de efetivo trabalho acadêmico. 


\section{RevistAleph}

As políticas públicas adotadas por necessidade de prevenção e combate à contaminação e proliferação da doença fizeram emergir uma modalidade de ensino que, apesar de ser "a distância", apresenta características próprias. Em razão disso, a fim de dissociá-la do EAD, essa nova modalidade passou a ser usualmente denominada de "ensino remoto", ou, ainda, "ensino remoto emergencial". Neste trabalho, chamamos de "ensino remoto" a adoção de diversas tecnologias e meios como instrumentos pedagógicos durante o isolamento social, tais como plataformas digitais, aulas por videoconferência, chats, redes sociais (Facebook e WhatsApp), podcasts ou videoaulas, além da comunicação por correios eletrônicos. O meio tecnológico adotado pode ser apenas o áudio (podcast) ou uma mescla de áudio e vídeo (videoaula).

Diante das discussões a respeito das finalidades e dos resultados nessa modalidade de ensino, a pergunta que surge no horizonte das expectativas é: ensino a distância, para que e para quem? Nesse sentido, o problema a ser investigado gira em torno dos meandros dessa modalidade na rotina dos estudantes durante o período investigado, haja vista que permanecem os antigos problemas que envolvem o binômio inclusão/exclusão digital, a despeito das novas tecnologias ou das boas intenções que nem sempre se realizam.

As realidades são diversas, e, neste trabalho, pretendemos abarcar o ensino remoto aplicado nas salas de aula da educação dos ensinos médio (rede estadual do Rio de Janeiro) e superior (instituição particular), resultante de nossa experiência como docentes, em um diálogo com a experiência de tutoria. Nossa intenção é refletir sobre a introdução de processos de ensino-aprendizagem desenvolvidos a partir de diversas mídias, sem o prévio preparo humano e metodológico, ante a ausência de fundamentos legais e curriculares estáveis e claros, para a adaptação do ensino presencial, cujas novas características estão enfatizadas na escolha dos epítetos remoto e emergencial.

As salas de aula presenciais, efetivamente, chegam ao século $\mathrm{XXI}$, tempo marcado pela difusão da internet. Se, antes, as tecnologias de informação e comunicação (TIC) já estavam presentes de alguma forma, com o isolamento social 


\section{RevistAleph}

imposto como medida de prevenção, elas invadiram com toda força a esfera da educação. Tudo indica que vieram para ficar, ao menos enquanto durar esse estado de incertezas e descontrole da saúde pública. Sabemos que é, ainda, uma história em construção, tanto que um dos primeiros desafios enfrentados na escolha do tema foi a utilização do termo "ensino a distância" para nomear as práticas atuais de ensino. Na realidade, as experiências vividas e as estratégias de ensino-aprendizagem, elaboradas, por meio de um modelo remoto, carecem de regulamentação, a fim de consubstanciarse efetivamente em uma modalidade de EAD ou de ensino híbrido. ${ }^{25}$

A presente análise volta-se para a área da Educação no cenário atual, a partir da observação dos usos das ferramentas comunicacionais, dos recursos tecnológicos adotados para acesso dos alunos aos conteúdos ministrados e da atuação dos professores, considerando as desigualdades geradas àqueles em situação de vulnerabilidade socioeconômica e os desafios cotidianos no ambiente virtual.

\section{“Para não dizer que não falei...". Reflexões sobre o campo da experiência}

Limitada a um modelo convencional, as escolas brasileiras, em grande medida, ainda estão distantes de inovações mais profundas, sejam elas digitais, curriculares, metodológicas ou avaliativas (MORAN, 2017, p. 72). Com a realidade imposta pelo combate ao novo coronavírus (COVID-19), emergiu, ainda que em caráter excepcional, uma nova prática sem precedentes. Para refletirmos o novo, faz-se necessário destacar a ampliação da utilização do EAD, tido como metodologia inovadora de aprendizagem. Nos últimos anos, a partir do Decreto no 9.057, de 25 de maio de 2017 (BRASIL, 2017); da Portaria no 1.428, de 28 de dezembro de 2018 (BRASIL, 2018), e da Portaria no 2.117,

\footnotetext{
25 Segundo Valente (2015, p. 21) “[...]o ensino híbrido é uma abordagem pedagógica que combina atividades presenciais e atividades realizadas por meio das tecnologias digitais de informação e comunicação (TDICS). Existem diferentes propostas de como combinar essas atividades, porém, na essência, a estratégia consiste em colocar o foco no processo de aprendizagem do aluno e não mais na transmissão de informação que o professor tradicionalmente realiza".
} 


\section{RevistAleph}

de 6 de dezembro de 2019 (BRASIL, 2019), a legislação tem possibilitado a ampliação da carga horária na modalidade de EAD em cursos presenciais, até o limite de $40 \%$ da carga horária total do curso. Ao adotarem o ensino a distância, os cursos não presenciais tendem, na maioria das vezes, a reduzir custos com professores, espaço físico, material, funcionários, energia elétrica, entre outros. Isso reflete diretamente no valor das mensalidades e, por consequência, no aumento da concorrência entre as instituições. A legislação tornou-se, assim, basilar para a adoção de políticas públicas voltadas para a ampliação de cursos e o funcionamento de instituições de educação a distância em níveis e modalidades distintos: ensino fundamental, ensino médio, educação profissional técnica de nível médio, educação de jovens e adultos e educação especial. ${ }^{26}$

Quando as atividades acadêmicas em nível superior foram suspensas, ou quando houve a antecipação das férias no âmbito fundamental de ensino, no último dia 16 de março, as autoridades responsáveis pela educação não podiam prever a extensão das medidas de isolamento social no ano letivo de 2020. O cenário de incertezas permanecia. A nova realidade impeliu a criação de modalidades substitutas à educação presencial de forma emergencial, sem que houvesse, contudo, tempo hábil para o treinamento prévio dos professores, bem como dos alunos.

No intuito de compreender essas mudanças tão rápidas, a metodologia aplicada na abordagem do tema - que versa sobre o ensino remoto em caráter emergencial, o EAD e o uso das tecnologias nos espaços acadêmicos - está centrada em um relato de experiências ocorridas na docência nos ensinos médio (rede estadual) e superior (rede particular). O escopo são as diversas atividades propostas pelos professores e, em parte, a aceitação e integração dos estudantes, desde que foram suspensas as aulas presenciais. Nossa intenção é avaliar as motivações, os desdobramentos e os consentimentos no uso das tecnologias digitais de informação e comunicação (TDICs) para implementação do ensino remoto emergencial.

\footnotetext{
${ }^{26}$ Art. 8으, incisos I ao V, do Decreto no 9.057, de 25 de maio de 2017 (BRASIL, 2017).
} 


\section{RevistAleph}

A análise qualitativa desses dados parte da ideia de que o espaço do ensino, mediado pelas novas tecnologias digitais na modalidade a distância, será mais bem compreendido na medida em que forem considerados dentro do campo da experimentação e, principalmente, da experiência. Nesse sentido, de acordo com Thompson (2004), é necessário entender as relações humanas dentro do campo das experiências culturais dos indivíduos que ressignificam o mundo que os cerca, conferindo sentidos próprios e específicos às relações institucionais e sociais.

No intuito de explicar a formação da classe operária inglesa, no período marcado pela Revolução Industrial, de acordo com Hunt (2006), Thompson elabora o campo do vivido ou "a maneira como se lida com essas experiências materiais... de modo cultural" (TRIMBERGER apud HUNT, p. 6). Para Thompson:

A experiência de classe é determinada, em grande medida, pelas relações de produção em que os homens nasceram - ou entraram involuntariamente. A consciência de classe é a forma como essas experiências são tratadas em termos culturais: encarnadas em tradições, sistema de valores, ideias e formas institucionais (THOMPSON, 2004, p. 10, grifo nosso).

No início da década de 1960, o historiador inglês Thompson publica o livro "A formação da classe operária inglesa", contando a trajetória de formação da classe operária nessa sociedade. Em uma mudança de perspectiva às explicações clássicas do marxismo, centradas no modelo estruturalista das instituições políticas, Thompson desvia-se para compreensão de uma história vista de baixo. Interessado no dia a dia do operário inglês e suas estratégias de autorregulação e sobrevivência, diante das rápidas transformações produtivas impostas pela Revolução Industrial que atravessaram os costumes da população, o autor ressignifica a ideia de classe. Tratava-se, portanto, do que ficou conhecido como marxismo revisionista, ou de uma história de inspiração marxista com um desvio para as mediações culturais (HUNT, 2006). Na obra, o autor distancia-se das explicações tradicionais sobre a formação de uma consciência exógena 


\section{RevistAleph}

à classe operária forjada no vanguardismo de um líder. Não; para Thompson, o conceito de experiência histórica do indivíduo explica o surgimento de uma consciência a partir dos engendramentos e dos códigos simbólicos que se estabelecem no dia a dia do ser humano em sociedade. O trabalho, que antes da Revolução era regulado pelo tempo da natureza, passou a ser regrado pela dureza do relógio que atravessava os costumes. De acordo com Thompson (2004), nas dificuldades de sobrevivência nos centros urbanos, nas perdas de identidade profissional - face aos novos mecanismos de produção em larga escala -, os indivíduos uniam-se no sentido de elaborar soluções para os problemas do cotidiano, pois:

[...] se examinarmos esses homens num período adequado de mudanças sociais, observamos padrões em suas relações, suas ideias e instituições. A classe é definida pelos homens enquanto vivem sua própria história e, ao final, essa é sua única definição (THOMPSON, 2004, v. I, p. 12).

O campo da experiência social e histórica é, portanto, segundo o autor, mais que as categorias estruturais e econômicas das teorias clássicas do marxismo. É aquilo que vai explicar a tomada de consciência de classe e a apropriação do sentido de autonomia no homem a partir da cultura:

Num determinado sentido, podemos descrever o radicalismo daqueles anos como uma cultura intelectual. [...] Na maioria dos ofícios artesanais, os oficiais e pequenos mestres consideravam como uma necessidade profissional um certo grau de leitura e trato com os números. [...] A capacidade de operar com argumentos abstratos e sucessivos não era absolutamente inata; tinha de ser descoberta à custa de dificuldades quase esmagadoras - a falta de tempo livre, o preço das velas, além das carências de formação (THOMPSON, 2002, v. III, p. 303; 311; 305).

Com efeito, uma das mudanças mais significativas impostas pela pandemia na área da Educação diz respeito à jornada de trabalho e a interação professor/aluno mediada pelas tecnologias digitais. Até onde sabemos, não há um consenso sobre o tempo de duração adequado para as aulas ofertadas na modalidade do ensino remoto 


\section{RevistAleph}

emergencial. Entretanto, é perceptível que trata-se de uma "jornada de trabalho intenso" (KIRCHNER, 2020, p. 51), e que exige da classe dos profissionais da educação múltiplas habilidades, que tiveram que ser aprendidas e ensinadas "à custa de dificuldades quase esmagadoras" (THOMPSON, 2002, p. 305). Na rede privada de ensino, por exemplo, o cronograma das avaliações se manteve, a despeito das dificuldades iniciais dos docentes e discentes com os aplicativos e com investimentos em internet e aquisição de acessórios de informática (notebook, fones, smartphones etc.).

Mas, conforme assevera Paulo Freire, "Ninguém começa a ser educador numa certa terça-feira às quatro horas da tarde [...]. A gente se faz educador, na prática e na reflexão sobre a prática" (apud FREITAS; FOESTER, 2016, p. 58), é preciso refletir também sobre o estranhamento e as dificuldades de adaptação às novas metodologias institucionais de ensino - com a efetiva utilização de tecnologias - da parte dos professores. De acordo com Thompson, a questão cultural esclarece determinadas práticas reativas dos trabalhadores às mudanças impostas, na medida em que interpretam a nova produção industrial em larga escala como uma perda de identidade profissional. Decerto, o estranhamento da classe docente com a modalidade do ensino a distância no contexto pandêmico, não se restringe às dificuldades cotidianas no manejo das novas tecnologias digitais. De acordo com Freire (1998), é sabido que parte da formação do educador se forja no dia a dia, nas dificuldades encontradas na prática profissional e nas estratégias de superação. E para Thompson (2002), é baseado em suas experiências que os indivíduos ressignificam as transformações e as dificuldades do seu tempo. Na condição de docente, há muitas questões que nos inquietam diante do cenário atual, entre as quais, a efetividade e o legado do ensino remoto e seus respectivos impactos para os profissionais da Educação.

Quanto aos discentes, tanto o estudante da educação básica, com acesso restrito às redes de comunicação digital nas escolas públicas das periferias, quanto os universitários, considerando-se que as disciplinas a distância, atualmente, podem 


\section{RevistAleph}

perfazer até $40 \%$ da grade dos cursos presenciais de graduação, também estão sujeitos às dificuldades de acesso às plataformas institucionais, que, ao contrário do que possa parecer, não são tão familiares a essa geração. Na introdução do livro Desafios da educação em tempos de pandemia (2020), Lorival Rambo destaca que há ganhos na agilidade da comunicação mediada pelas tecnologias digitais que podem ser observados mesmo dentro de uma conjuntura emergencial e caótica, como tem sido esse período pandêmico. Entretanto, "para quem, infelizmente, tenha algum fator limitante, mesmo que seja somente falta de disciplina, terá perdas proporcionais" (RAMBO, 2020, p. 18). A falta de preparo de docentes e discentes para o ensino remoto pode prejudicar o aproveitamento das TDICs que estão sendo utilizadas e, nesse sentido, inviabilizar o alcance do objetivo, que é o ensino-aprendizagem. Entretanto, acreditamos que as experiências do ensino remoto emergencial são uma oportunidade de compartilhando erros e acertos - reelaborar caminhos e práticas para a educação. Para isso, a prática que adquirimos com a utilização das plataformas digitais no dia a dia, alinha as perspectivas do relato pessoal de tutoria e de docentes de ensino médio e superior com o cotidiano desses estudantes nos marcos eleitos sob a abordagem do conceito de experiência.

O fato é que, habilitadas ou não para a nova realidade virtual, tivemos que encontrar meios emergenciais para interagir com nossos estudantes. Aliás, muitos deles nos acessaram primeiro (Fonte: As autoras).

Na rede estadual de ensino, inicialmente, foram suspensas as aulas e as duas primeiras semanas de isolamento social corresponderam ao recesso escolar. Passado este período, a primeira semana do mês de abril foi para acertos e adequações com relação ao uso da plataforma digital escolhida para manutenção das aulas - o Google Classroom. Inúmeras foram as dificuldades encontradas, tanto para os docentes quanto para os discentes. Como não houve um preparo para utilização da referida plataforma,essa tendeu para o uso intuitivo, cada parte tentou e/ou adaptou-se da melhor maneira e coube aos professores desenvolver métodos para estimular o aluno 


\section{RevistAleph}

a enfrentar o novo desafio. No outro lado da tela, a maioria dos alunos mostrou-se desestimulada com as dificuldades de acesso, outros ainda tiveram que enfrentar a impossibilidade de contratar planos de internet e adquirir dispositivos eletrônicos. Somado a esses fatores, acreditamos que o maior desafio enfrentado por todos os envolvidos no processo foi a falta de preparo, prática e conhecimento em aulas virtuais mediadas através de plataformas digitais.

No curso de licenciatura em História, a estratégia institucional para manter parte do cronograma foi a adoção de estudos dirigidos elaborados pelos professores e enviados aos estudantes através do Portal. Ainda assim, os alunos entravam em contato por e-mail, ou por WhatsApp, no intuito de saber quais seriam as próximas estratégias para manutenção do período. Mas naquele momento, nós não tínhamos essas respostas. Em pouco tempo, tivemos que assumir determinadas funções, elaborando, testando e reelaborando várias formas de interação com o estudante. No início, não havia um consenso sobre o melhor aplicativo para as aulas virtuais, e isso era o suficiente para recrudescer os ânimos dos estudantes. Para a primeira aula, usamos um aplicativo da escolha da maioria da turma, mas logo depois vieram as manifestações de dificuldades em baixar o aplicativo nos aparelhos de celular, da falta de acesso a uma internet de qualidade e de dispositivos adequados para o acesso. Mudamos de aplicativo três vezes durante o primeiro semestre. Somava-se às dificuldades com as tecnologias digitais os problemas socioeconômicos, o desemprego, a enfermidade e as vidas perdidas de amigos e parentes. Foi nesse contexto caótico que seguimos ministrando nossas aulas virtualmente. ${ }^{27}$

Quanto a nossa atuação na tutoria das disciplinas ministradas na modalidade EAD na outra instituição de ensino superior, imaginávamos que não haveria grandes impactos administrativos, haja vista que o cronograma de aulas e o calendário das atividades avaliativas pressupõe a mediação a distância. Entretanto, o fato de todo o

\footnotetext{
${ }^{27}$ Fonte: as autoras.
} 


\section{RevistAleph}

ensino presencial ofertado na faculdade de uma hora para outra migrar para a modalidade a distância ensejou uma série de ruídos na comunicação. O estudante entrava em contato com a tutoria de EAD, solicitando explicações sobre como proceder em seus estudos nas disciplinas, mas ele próprio não sabia informar se se tratava das disciplinas presenciais ofertadas remotamente por conta da pandemia, ou se era de fato as disciplinas ofertadas na modalidade $100 \%$ EAD. No primeiro momento, precisamos compreender o que o estudante não estava entendendo, ou o que gostaria de dizer, para proceder uma orientação adequada. Ademais, percebemos que havia uma resistência e/ou dificuldade dos estudantes em ler os informativos disponibilizados virtualmente. Não foi fácil. ${ }^{28}$

\section{"Ensinando e aprendendo uma nova lição": a autonomia e o ensino a distância}

Ao abordar a temática da educação a distância nos espaços acadêmicos - mais especificamente a escola e a universidade - , pretende-se problematizar algumas ideias que, no mais das vezes, são naturalizadas como inerentes aos ingressantes nos espaços do ensino a distância, ou, em última análise, como característica adjacente aos estudantes do século XXI. Isso, em certa medida, alinha-se à propagação das mídias sociais e das novas TDICs no cotidiano das pessoas. A despeito do lugar-comum de outros trabalhos sobre o EAD - que trouxeram relevantes críticas sobre a temática -, importa perceber os equívocos ou a construção de pressupostos ao perfil desses estudantes - aparentemente autônomos, para transitar nesse universo digital, quando desconsiderada sua realidade sociocultural - que expõe a necessidade de rever algumas teorias e práticas atreladas ao cotidiano dessa modalidade.

A valorização da autonomia nos espaços virtuais surge como ente, ou característica sine qua non, para o sucesso (ou fracasso) da aprendizagem no ensino

\footnotetext{
${ }^{28}$ Fonte: as autoras.
} 


\section{RevistAleph}

mediado pelas tecnologias digitais. Todavia, o conceito de autonomia carece ser compreendido dentro dos limites culturais dos grupos de estudantes que perfazem essas localidades. Para tanto, um dos desafios diários às práticas docentes nesse ambiente é não perder de vista a subjetividade na interação com o educando. Grosso modo, que o ensino a distância seja uma oportunidade dinâmica de comunicação, permitindo, assim, maior aproximação e compreensão das dificuldades e especificidades de cada segmento estudantil.

Na obra Pedagogia da Autonomia (1998), Paulo Freire discute a emancipação do educando como um processo em construção baseado na realidade do indivíduo e reforça a importância da mediação do educador para a formação do sujeito autônomo, um ser "artífice de sua própria formação" (FREIRE, 1998, p. 42). Para tanto, o autor informa a necessidade de o professor entender o educando como um ser situado no tempo e em sociedade.

A aprendizagem autônoma, valorizada na educação a distância como um princípio pelo qual o estudante "[...] é identificado e se identifica como indivíduo administrador dos conhecimentos adquiridos" (ZUIN, 2006, p. 946), na prática demanda do professor excessivas funções, no intuito de auxiliar o processo de autossuficiência do estudante do ensino presencial.

O olhar crítico sobre o conceito de autonomia atrelado ao EAD faz-se necessário especialmente quanto à realidade local e regional do público ao qual se destina. Zuin (2006, p. 946 e 947) discute que, a linha entre a autoridade e o "autoritarismo da imagem" em uma sociedade marcada por relações constituídas na truculência da recente ditadura militar no Brasil forjou, em grande medida, um indivíduo/consumidor passivo dos espetáculos audiovisuais, especialmente nas periferias dos grandes centros urbanos, com acesso restrito à diversidade de lazer e educação. Assim sendo, um veículo de comunicação de massa, como a internet, corrobora uma certa dependência na aquisição de informações e conteúdos que, muitas vezes, se mostram falsos (fake news), mas que ocupam um espaço vazio de formação e 


\section{RevistAleph}

informação na vida do sujeito, em uma dialética entre os limites da autonomia e da anti autonomia do educando. O reducionismo em torno de uma pretensa facilidade e liberdade de acesso às TDICs, como algo dado a essa geração digital, obscurece a realidade cotidiana e dificulta a reelaboração de práticas que não funcionam. Uma das características desejáveis do professor e do tutor na educação a distância - cujas práticas são mediadas pelas tecnologias - é o de ser um estimulador do desenvolvimento crítico dos seus educandos, voltado para o próprio conteúdo. Entretanto, uma parte significativa dos professores também não está incluída nos meandros do universo digital.

Nesse sentido, o entrelaçamento que se estabelece entre a "educação a distância" e a "educação distante" (ZUIN, 2006, p. 942) traz para a arena das discussões as (im)possibilidades de atuação do professor e do tutor nessa nova perspectiva de formação acadêmica. Nesse sentido, cabe perguntar: "Pode um processo educativo/formativo ser desenvolvido à distância?" (ZUIN, 2006, p. 945).

Para refletir sobre o conceito de educação a distância, Silva e Toschi (2015, p. 62) definem o EAD como "[...] uma forma de ensino que se difere do ensino presencial devido a características pontuais: novos espaços de aprendizagem, nova relação professor-aluno e intensificação na utilização de recursos tecnológicos". As autoras esclarecem que a didática nessa modalidade não deve ser compreendida como simples. O EAD constitui uma:

[...] transposição de práticas bem-sucedidas no ensino presencial, mas tem vida própria, tem especificidades que prezam por uma organização didático-pedagógica que, mais do que refletir sobre a distância ou separação física e geográfica, necessita pensar em como superar essa dicotomia (SILVA; TOSCHI, 2015, p. 71).

Com efeito, a comunicação e o diálogo adquiriram novas dimensões no ambiente virtual de aprendizagem (AVA). Se, por um lado, vivemos sob os riscos de uma tendência às manifestações audiovisuais espetaculares - e, nesse sentido, situados em um tempo e espaço em que se produz indivíduos "solitariamente conectados" -, por 


\section{RevistAleph}

outro, estamos diante de uma cultura em movimento que se reinventa e está atuante nas mudanças sociais. É sabido que o diálogo não se estabelece na inércia, ou seja, por melhores que sejam as condições dos recursos tecnológicos e a economia de tempo (um dos ganhos apontados no EAD), as práticas pedagógicas precisam ser estabelecidas e assumidas pelas pessoas que se dispõem a educar, sem as quais o ensino-aprendizagem não se realiza. Doravante, esta reflexão se estende à modalidade presencial, haja vista "que a distância é um fenômeno pedagógico, e não simplesmente uma questão de distância geográfica [...]" (MOORE; KEARLEY, 2013 apud SILVA; TOSHI, 2015, p. 74).

Retoma-se, portanto, a discussão do conceito de autonomia do estudante, sobre o qual se ensejam diferentes estágios de desenvolvimento humano. A emancipação, stricto sensu, deve ser entendida como um processo no qual cada caso é um caso. Por outro lado, há que se pensar nas possibilidades que o AVA propicia e estimula a um número cada vez maior de pessoas, funcionando como uma espécie de laboratório para um antigo desejo dos engajados no processo educacional: um sujeito capaz de elaborar e ressignificar o conhecimento no uso que lhe confere. Portanto, de acordo com a referência de Zuin sobre a "nova" modalidade de ensino: "Mas onde há o perigo, cresce também o que salva" (HOLDERLIN apud ZUIN, 2006, p. 1).

De acordo com Silva (2010), termos como interface, web, hipertexto, hiperlink e interatividade etc. matizam as discussões sobre metas a serem alcançadas no mundo corporativo e no espaço acadêmico, para as quais:

[...] a formação de professores para docência online carece do investimento atento ao contexto sócio-técnico e comunicacional da cibercultura, sob pena da subutilização das potencialidades operativas e colaborativas das interfaces do computador e da web e do prejuízo à educação autêntica baseada nas metodologias dialógicas (SILVA,2010, p. 36).

A discussão sobre o lugar das práticas docentes no AVA perpassa essa valoração tecnicista - como abordado anteriormente neste trabalho - guardada a devida importância que os recursos tecnológicos têm a oferecer nesse ambiente. Todavia, é 


\section{RevistAleph}

preciso mais que estrutura física e tecnológica para se chegar à dita educação autêntica, haja vista que nem sempre interação se traduz em relação dialógica.

A despeito das críticas à excessiva valorização das tecnologias digitais em nosso dia a dia, o extremo oposto a esse debate é o binômio inclusão/exclusão digital, tanto do docente quanto do discente. Por inclusão digital, Silva (2010, p. 36) compreende “[...] acesso ao computador conectado à internet e saber lançar mão de suas interfaces para expressão do estar-junto colaborativo online ou para presença virtual". De fato, os instrumentos virtuais não foram feitos pensando na educação, mas é necessário criar adequações para o ensino, do contrário não haverá inclusão, tampouco ganhos reais para essa área. Na prática, ainda temos professores que pouco acessam o correio eletrônico, não desenvolvem pesquisas acadêmicas utilizando a internet, sequer utilizam seus smartphones para ter acesso a jogos, séries ou filmes. Enfim, alguns docentes ainda oferecem resistência em relação a trabalhar, pesquisar e se comunicar via web (SILVA, 2009).

O atual problema de saúde pública que enfrentamos coloca em evidência como a relação com o mundo virtual é diferente para docentes e discentes. Na prática, muitas vezes, encontramos professores ainda analógicos e alunos tecnológicos. Queiroz (2016), na elaboração de sua dissertação em 2016, ao abordar o cibridismo (capacidade cada vez maior de estar conectado, na qual "algumas pessoas ainda transitam entre as redes on e offline" enquanto outras "já são online") destacou os alunos enquanto sujeitos digitais, que além de

[...] terem as TICs como extensões de seus corpos e mentes, eles ampliaram seus seres para os seus perfis online em plataformas de redes sociais. Estão constantemente presentes, não fisicamente, mas virtualmente. Seus celulares estão conectados e, por isso, podem ser contatados a qualquer momento, podem ser curtidos, cutucados, compartilhados, stalkeados, retwitados a qualquer momento (QUEIROZ, 2016, p. 35, grifo do autor). 


\section{RevistAleph}

A despeito da autora analisar o âmbito da sala de aula presencial, aspectos referentes à resistência de alguns professores em adequar suas práticas à realidade digital, tornou-se um agravante na pandemia. Muitos docentes que defendiam a sala de aula presencial como espaço para "desconectar do mundo digital e focar" viram-se sem escolhas, desafiados não apenas em se inserir no espaço virtual instantaneamente, como a tomar parte dele como instrumento para exercer seu ofício. Nesse sentido, a instauração do ensino remoto emergencial permite entrever os efeitos da ausência de políticas públicas e sociais de formação e inclusão digital dos profissionais de educação, que poderiam favorecer a adaptação desses docentes ao universo digital desses alunos, bem como as medidas emergenciais utilizadas para manutenção do sistema educacional no período pandêmico.

Se professores resistentes à tecnologia e excluídos digitalmente constituem uma realidade e se "ninguém nasce cidadão, muito menos cidadão digital", como formar cidadãos digitais? Se "a cidadania é apre(e)ndida no decorrer da vida (...) nossos alunos precisam ser ensinados, conduzidos à cidadania digital" pelos professores, respeitandose todos os seus nove elementos

[...] etiqueta digital, comunicação digital, letramento digital, acesso digital, comércio digital, lei digital, direitos e responsabilidade digital, saúde e bem-estar digital e segurança digital (auto-proteção) (QUEIROZ, 2016, p. 41).

Segundo Borges (2008, p. 179) "a Sociedade da Informação e do Conhecimento é reconhecida pelo uso intenso da informação, do conhecimento e das tecnologias da informação e da comunicação, na vida do indivíduo e da sociedade, em suas diferentes atividades". Nessa nova sociedade, o uso intenso das informações e a rapidez na circularidade delas desafiam os profissionais voltados para a educação básica a lidar com a quantidade do que se produz e se reproduz na internet, por exemplo, sob uma análise crítica dos conteúdos. Nos centros universitários, a forma de comunicação mediada pelas tecnologias (fórum, correio eletrônico, webconferência, blog etc.) - no caso dos 


\section{RevistAleph}

cursos a distância ou da oferta de disciplinas a distância - servirá como um recurso ou técnica para o estudo. O ensino remoto emergencial, por sua vez, coloca em evidência a necessidade da adequação dos Projetos Político-Pedagógicos, a fim de promover a interação e inclusão digital. Isso compreende o aparelhamento das escolas com equipamentos eficazes (como computadores e wi-fi), bem como a formação e inclusão digital dos docentes.

“E agora, José? José, para onde?": os (des)caminhos da educação em tempos de pandemia.

E agora, José?

A festa acabou,

A luz apagou,

O povo sumiu,

A noite esfriou

$[\ldots]$

A noite esfriou,

O dia não veio,

O bonde não veio,

O riso não veio

[...]

E agora, José?

("José", de Carlos Drummond de Andrade)

Sexta-feira, 13 de março de 2020.

No momento em que os meios de comunicação informavam as primeiras medidas temporárias de prevenção ao contágio e de enfrentamento à propagação da COVID-19, duas professoras, colegas de trabalho, situavam-se em lados opostos da cidade do Rio de Janeiro, dividindo as mesmas incertezas. Uma decidia se entrava ou não no trem em direção à faculdade para dar aula no período noturno; outra, em uma reunião informal com amigos da área de saúde, procurava entender melhor o motivo das medidas tomadas pelo governo estadual. Naquele momento, a notícia pegou todos desprevenidos. Muitos ainda especulavam se as medidas não seriam exageradas ou descabidas, e a desinformação dividia as opiniões. O fato é que nossa geração, do dia para a noite, se defrontava com sua primeira, vasta e mortal pandemia. 


\section{RevistAleph}

Como de costume, no horário do rush carioca, os vagões dos trens passavam abarrotados em direção ao subúrbio da cidade. Dessa vez, porém, o desconforto e a insegurança do transporte público de massa sinalizavam um novo perigo: contágio, doença e morte. Logo, o medo se misturou à difícil escolha de ter que desistir da aula de sexta-feira, já que a instituição de ensino superior ainda não tinha decidido pela suspensão das aulas - a decisão do governo estadual só suspenderia as aulas no estado a partir da segunda-feira seguinte. Daquele dia em diante, porém, a única certeza que tínhamos era de que todo o planejamento do semestre estava seriamente comprometido.

A partir daquela sexta-feira, o ano letivo de 2020 não seria mais o mesmo para nenhuma das duas. Em 15 dias, o ensino remoto emergencial foi estabelecido em quase todos os níveis educacionais, quer fossem estabelecimentos de ensino públicos ou particulares. A modalidade de ensino aplicada como resposta à necessária continuidade das atividades escolares, inicialmente, causou certo estranhamento a discentes e docentes, conforme indicamos anteriormente.

Os profissionais precisaram se adaptar, sobretudo - aqueles não pertencentes ao grupo dos sujeitos digitais e sem qualquer familiaridade com as TDICs. A resistência dos discentes foi mais contundente, e nossa experiência confirma a permanência de tal comportamento até o presente momento nas nossas turmas de ensino médio em nível estadual. As medidas de prevenção ao contágio e de enfrentamento à propagação do novo coronavírus, impuseram várias medidas restritivas, dentre as quais o estudo realizado dentro de casa. Tal situação desagradou diretamente os jovens, geralmente, mais questionadores e tendentes a não aceitar imposições. Entre as reclamações mais recorrentes, podemos citar: não poder sair de casa, não poder confraternizar com os amigos, ter que dialogar com uma tela, não ter a explicação direta do professor etc. As queixas chegaram na velocidade própria da era digital: fomos bombardeadas por $e$ mails e mensagens instantâneas de estudantes desestrumentalizados para o ensino remoto. 


\section{RevistAleph}

Em contrapartida, no ensino superior privado, identificamos comportamento diverso, grande parte dos alunos percebeu a importância e a utilidade da aplicabilidade do ensino remoto emergencial e buscou a superação das dificuldades de acesso às plataformas digitais, a fim de garantir a continuidade do curso sem prejudicar seu término. Embora o curso universitário em destaque esteja vinculado a uma instituição particular, faz-se primordial destacar que o perfil socioeconômico dos alunos interferiu na participação das aulas remotas. A exclusão digital mesclou alunos de grupos etários mais elevados (com mais dificuldades de adaptação à realidade virtual), moradores de áreas em que o serviço de internet não estava disponível, bem como aqueles dispensados do trabalho ou que perderam o meio de subsistência familiar e, por isso, se viram impedidos de contratar o serviço de internet.

Queiroz (2016, p. 32) analisa a questão da exclusão digital, não apenas pelo viés socioeconômico, mas também como uma questão de gerações, reforçada pelo modelo presencial de ensino que, antes da pandemia, não integrava as TIDCs em suas práticas pedagógicas. Durante a pandemia, realmente, alunos, geralmente de faixa etária mais elevada, acostumados com as aulas presenciais e sem habilidade com as tecnologias tenderam a demonstrar mais dificuldade em adaptar-se às aulas virtuais. Nossa prática docente comprova a atualidade da afirmação da autora de que "a inclusão digital para alguns alunos é ter um 3 ou 4G pré-pago, no qual o acesso ilimitado restringe-se às redes sociais (facebook, whatsapp), não a internet".

Estamos todos, professores e alunos, no campo do aprendizado ao enfrentar diariamente cada novo desafio e, nesse sentido, reavaliando antigas convicções. Professores formados no e para o ensino presencial se veem impelidos a desenvolver habilidades múltiplas, produzir, editar e gravar video aulas, elaborar materiais específicos para o ambiente virtual (como se fossem tutores de EAD), participar de frequentes reuniões de planejamento, no mais das vezes sem critério de horário, e escancarar sua vida privada (ao disponibilizar números de telefones particulares e gravar aulas dentro dos seus lares). No exercício de suas funções, os professores têm 


\section{RevistAleph}

necessitado muito mais do que esforços conjuntos e criatividade para enfrentar as adversidades impostas pelo isolamento social.

Atuando como tutora, percebemos manifestações de ansiedade e baixa autoestima daqueles professores que apresentavam maiores dificuldades com o uso das tecnologias digitais, especialmente com inúmeros aplicativos e plataformas para as webconferências. Não por acaso, ouvimos colegas de profissão, com anos de experiência no ensino presencial, questionarem sua própria competência para continuar ensinando. Decerto, a invisibilidade dos docentes corrobore esse sentido, na medida em que a ausência dos professores nas consultas públicas sobre o retorno às aulas em meio à pandemia denota um grave indício do descaso sobre o papel e a importância desse profissional no contexto.

A ausência de formação de tutoria em EAD e a falta de familiaridade com os elementos da estrutura dessa modalidade obstaram a compreensão efetiva e imediata do modelo de ensino remoto emergencial adotado pelas instituições de ensino. Contudo, o despreparo para lecionar no ambiente virtual, coordenando atividades assíncronas e síncronas, não pode ser visto como incapacidade ou incompetência dos docentes. Destacamos aqui a situação sui generis do distanciamento vivido no ensino remoto emergencial, pois mesmo a metodologia empreendida no EAD não constitui necessariamente o isolamento do aluno, um rompimento ou distanciamento na relação deste com o professor. Há, no EAD, uma heterogeneidade de atividades, em parte necessariamente cumpridas na forma presencial (por exemplo, na utilização de laboratórios de informática para acesso coletivo ou no agrupamento de diversos cursos simultaneamente para a realização das provas presenciais), o que, de fato, não acontece nesse ensino remoto.

Quanto à experiência de tutoria no EAD, importa destacar que o estudante é orientado pelo tutor, desde o primeiro acesso, a mover-se dentro do ambiente e, utilizar os recursos, clicando nos ícones e rótulos de informação. A abertura das unidades e dos conteúdos semanais são informados em espaços determinados, como o Quadro de 


\section{RevistAleph}

Avisos, localizado no ambiente virtual da disciplina. As datas das avaliações são postadas na Agenda da Disciplina no início do semestre. No entanto, de todas as solicitações de auxílio no ambiente, a mensagem mais recorrente é sobre o local de postagem dos conteúdos, por mais que isso nos pareça evidente. No atendimento presencial semanal, a maioria dos estudantes informava nunca ter acessado os espaços de informação. Outros argumentavam não saber como acessá-los, a despeito do tutorial de informação e da sinalização em destaque do ícone no ambiente. Mesmo os que nos procuraram presencialmente com essa solicitação, voltavam a fazê-lo ou enviavam mensagens perguntando sobre a localização dos informativos. Nesse lapso de tempo entre a pergunta, a resposta e a verificação do estudante, houve casos de perda de prazos para o cumprimento das atividades. Então, além das postagens destacadas no ambiente e dos avisos postados no quadro e enviados por e-mail aos estudantes, passou-se a divulgar, de forma mais contundente, a abertura das atividades avaliativas nos murais presenciais dos campi. Outra estratégia foi estabelecer uma parceria com os representantes de turmas dos cursos presenciais, visando à divulgação do calendário avaliativo. Alguns estudantes informaram não ter o hábito de acessar os e-mails institucionais com frequência, tampouco entrar no ambiente para acessar os conteúdos.

O que ficou colocado, tanto nas trocas de mensagens quanto no atendimento presencial a esses alunos, é que, apesar de ausentes, a grande maioria sabia que estava matriculada e que precisava acessar a disciplina. São recorrentes os comentários do tipo: "Estou priorizando as disciplinas presenciais" ou "Quando teremos aulas presenciais do EAD?". Isso demonstra, em parte, o que temos argumentado até aqui sobre a formação de uma consciência a respeito do lugar do ensino a distância na realidade desses estudantes.

Com efeito, a prática da tutoria não tem como função forjar, na classe de estudantes, a consciência da importância do acesso às disciplinas em EAD. A mediação atenta possibilita encontrar caminhos que levem à conciliação entre o que é desejável e o que é possível. Ademais, a despeito dos mecanismos institucionais, alguns 


\section{RevistAleph}

estudantes encontraram meios mais familiares de garantir o acesso às informações criando, por exemplo, grupos de WhatsApp. No cotidiano do EAD, as regras são reinventadas no uso que os estudantes fazem delas. Mediar esses processos, sem, contudo, cercear a criatividade, é um desafio. Convencer o estudante da necessidade de utilizar os meios disponíveis e interagir com o ambiente pressupõe estratégias de tutoria que provoquem respostas. É preciso indagar quantas vezes por semana o estudante se dispõe a entrar em seu ambiente virtual; sugerir que coloquem a agenda da disciplina na tela do seu celular; convidá-los a participar das webconferências como um recurso para esclarecer dúvidas diretamente com o professor da disciplina; enfim, destacar as vantagens.

Pensar o outro dentro de sua especificidade é um desafio ainda maior quando se trata de ensino a distância. O importante é não perder de vista a subjetividade na interação. As mensagens ao tutor - queixas e elogios ao ambiente - em muitos momentos, estão permeadas de desabafos e relatos pessoais. No ensino a distância, o elemento humano permanece no processo, ainda que mediado pelas tecnologias.

As questões aqui formuladas reiteram a diferença entre a utilização de atividades online, plataformas digitais e redes sociais como metodologia em tempos de pandemia (ensino remoto emergencial) e a utilização de ambientes virtuais de aprendizagem como modalidade de ensino a distância (EAD). Sabemos das dificuldades enfrentadas por docentes e discentes, mas ao professor coube a difícil tarefa de ficar na linha de frente para executar uma modalidade que não foi por ele escolhida nem construída. Uma imposição hierárquica, apressada, sem treinamento, dificultada pela resistência dos alunos; uma modalidade inventada de ensino, uma vez que a utilização de plataformas e ambientes virtuais não consubstanciam EAD, cuja metodologia é estruturada e completamente diferente.

Por outro lado, destacamos que a cultura digital trouxe um ganho exponencial com a realização de fóruns e lives por profissionais que são referência nas diversas áreas de ensino, inclusive, aqueles residentes fora do país. À luz do que abordamos neste 


\section{RevistAleph}

trabalho, defendemos a permanência e a utilização das atividades online (através de oficinas, lives no YouTube/Facebook/Instagram) como recurso didático. Não há que se falar apenas em perdas, pelo contrário, a pandemia fez muitos pais manifestarem a percepção sobre os desafios enfrentados pelos professores de seus filhos (destaque para a importância da escola enquanto instituição necessária ao funcionamento político, social e econômico do país).

Entretanto, no cenário caótico da pandemia, enquanto sociedade e governantes especulam o retorno às aulas presenciais, os profissionais da educação continuam todos "José", interlocutores a buscar no ordinário cotidiano a expiação de incertezas e dúvidas, a partir da dicotomia do existir-resistir.

\section{Conclusão}

Refletir e escrever sobre nossas experiências docentes durante a pandemia, em última análise, é uma forma de auxiliar nosso exercício diário de expiação de incertezas, mas também uma maneira de reorganizar as ideias. Por outro lado, há sempre o risco de uma análise parcial dos fatos, pois estamos tratando de uma história em movimento. Contudo, as emergências cotidianas que se avolumaram, forjaram um cenário social tanto caótico quanto carente de explicações e reordenamentos, diante de soluções e respostas que eram todas para ontem. Foi assim, sem muito tempo para organizar a reação que nos vimos da noite para o dia encapsulados nas telas digitais, autorizando e recorrendo aos objetos até pouco tempo indesejados nas salas de aula presenciais. Os aparelhos que competiam com a nossa atenção passaram a ser solicitados e necessários.

Diante de tudo o que foi discutido neste texto em torno do ensino remoto emergencial no contexto da pandemia, o binômio inclusão/exclusão digital torna evidente antigos problemas, como a desigualdade social, a frágil infraestrutura de núcleos de informática nos espaços acadêmicos e a falta de investimentos na capacitação e valorização dos docentes. De fato, os meios de comunicação informam que nenhum país do mundo estava preparado para este cenário pandêmico, e que a 


\section{RevistAleph}

área da Educação foi um dos setores mais atingidos. Mas, decerto, as dificuldades de comunicação a partir do ensino a distância, no caso brasileiro, estão relacionadas também às deficiências de formação dos estudantes na modalidade presencial. No ensino a distância, a leitura é um fator essencial para a comunicação professor/aluno e para o êxito na apreensão dos conteúdos. A experiência docente no ensino remoto demonstra que a dificuldade dos estudantes com a leitura - especialmente dos informativos e dos conteúdos disponibilizados virtualmente - foi um complicador no processo de ensino-aprendizagem mediado pelas tecnologias digitais, o que diretamente afeta o princípio do desenvolvimento da autonomia do estudante para o ensino a distância.

Do ponto de vista profissional, não tivemos margem para escolhas. Passamos a atender uma série de demandas de vários segmentos: famílias, estudantes, instituições de ensino e governo. Desenvolvemos metodologias para fazer valer esse ensino remoto, no intuito de alcançar o maior número possível de alunos, atuando, inclusive, como tutores de informática.

$\mathrm{Na}$ impossibilidade de vislumbrar o dito novo normal, sem data para uma vacinação em massa que garanta a toda comunidade acadêmica um retorno minimamente seguro às salas de aula presenciais, seguimos virtualmente, ajustandonos às demandas institucionais, sociais e políticas, e, nesse sentido, cada dia é um dia. A ironia, é que, das múltiplas tarefas atribuídas ao professor nesse período, pouco se sabe sobre sua opinião quanto ao retorno escolar.

A partir desse breve relato, buscamos compartilhar nossas impressões, sentimentos e reflexões sobre essa experiência singular, pois acreditamos que é ouvindo as comunidades escolar e acadêmica e, especialmente, considerando o que o professor tem a dizer que encontraremos caminhos para a Educação nesses tempos de pandemia.

\section{Referências Bibliográficas}




\section{RevistAleph}

ANDRADE, Carlos Drummond. E agora, José? Disponível em:

https://www.culturagenial.com/poema. Acesso em: 05 dez. 2020.

BORGES, M. A. G. A informação e o conhecimento como insumo ao processo de desenvolvimento. Revista Ibero-americana de Ciência da Informação (RICI), v.1, n. 1, p.175196, jul/dez 2008. Disponível em:

https://periodicos.unb.br/index.php/RICl/article/view/1249. Acesso em: 20 mar. 2020.

BRASIL. Decreto n. 5800, de 8 de junho de 2006. Dispõe sobre o Sistema Universidade Aberta do Brasil - UAB. Diário Oficial da União, Brasília, 9 jun. 2006.

BRASIL. Decreto no 9.057, de 25 de maio de 2017.

Regulamenta o art. 80 da Lei no 9.394, de 20 de dezembro de 1996 , que estabelece as diretrizes e bases da educação nacional. Diário Oficial da União, Brasília, 26 mai 2017. Disponível em: http://www.planalto.gov.br/ccivil_03/_ato20152018/2017/decreto/d9057.htm. Acesso em: 31 out. 2020.

BRASIL. Ministério da Educação. Gabinete do Ministro. Portaria no 343, de 17 de março de 2020. Dispõe sobre a substituição das aulas presenciais por aulas em meios digitais enquanto durar a situação de pandemia do Novo Coronavírus - COVID-19. Diário Oficial da União, Brasília, DF, 18 mar 2020a. Disponível em: https://www.in.gov.br/en/web/dou/-/portaria-n343-de-17-de-marco-de-2020-248564376. Acesso em: 31 out. 2020.

BRASIL. Medida Provisória no 934, de 1 de abril de 2020. Estabelece normas excepcionais sobre o ano letivo da educação básica e do ensino superior decorrentes das medidas para enfrentamento da situação de emergência de saúde pública de que trata a Lei no 13.979, de 6 de fevereiro de 2020. Diário Oficial da União, Brasília, DF, 10 abr. 2020b. Disponível em: http://www.planalto.gov.br/ccivil_03/_ato2019-2022/2020/mpv/mpv934.htm. Acesso em: 31 out. 2020.

BRASIL. Ministério da Educação. Gabinete do Ministro. Portaria № 1.428, de 28 de dezembro de 2018. Dispõe sobre a oferta, por Instituições de Educação Superior - IES, de disciplinas na modalidade a distância em cursos de graduação presencial. Diário Oficial da União, Brasília, DF, 31 dez. 2018. Disponível em: https://www.in.gov.br/materia//asset_publisher/Kujrw0TZC2Mb/content/id/57496468/do1-2018-12-31-portaria-n-1-428-de28-de-dezembro-de-2018-57496251. Acesso em: 31 out. 2020.

BRASIL. Ministério da Educação. Gabinete do Ministro. Portaria no 2.117, de 6 de dezembro de 2019. Dispõe sobre a oferta de carga horária na modalidade de Ensino a Distância - EaD em cursos de graduação presenciais ofertados por Instituições de Educação Superior - IES pertencentes ao Sistema Federal de Ensino. Diário Oficial da União, Brasília, DF, 11 dez. 2019. Disponível em: https://www.in.gov.br/en/web/dou/-/portaria-n-2.117-de-6-de-dezembro-de2019-232670913. Acesso em: 31 out. 2020. 


\section{RevistAleph}

COSTA, V. A. da; LEME, É. S. Tecnologia na educação. Desafios à formação e à práxi. Revista Iberoamericana de Educação, no 65, p. 135 - 148, maio de 2014. Disponível:

https://rieoei.org/historico/documentos/rie65a08.pdf. Acesso em: 29 ago. de 2020.

FREIRE, P. Pedagogia da Autonomia: Saberes necessários à prática educativa. Rio de Janeiro: Paz e Terra, 1998.

FREITAS, A. L. S. de; FORSTER, M. M. dos S. Paulo Freire na formação de educadores: contribuições para o desenvolvimento de práticas crítico-reflexivas. Educar em Revista, Curitiba, n. 61, p. 55-69, jul./set. 2016. Disponível em: https://www.scielo.br/scielo.php?pid=S0104-

40602016000300055\&script=sci_abstract\&tlng=pt. Acesso em: 29 ago. 2020.

HUNT, L. A Nova História Cultural. São Paulo: Martins Fontes, 2006.

KIRCHNER, E. A. Vivenciando os desafios da Educação em tempos de pandemia. In: PALÚ, J; SCHUTZ, J. A.; MAYER, L. (Org.). Desafios da educação em tempos de pandemia. Cruz Alta: Ilustração, 2020, p. $45-53$.

MORAN, J. Como transformar nossas escolas: novas formas de ensinar a alunos sempre conectados. In: CARVALHO, M. (org.). Educação 3.0: novas perspectivas para o ensino. Porto Alegre:Sinepe/RS/Unisinos, 2017, p. 63 - 87. Disponível em: http://www2.eca.usp.br/moran/wp-content/uploads/2017/08/transformar_escolas.pdf. Acesso em: 24 out. 2020.

QUEIROZ, A. P. C. Escolas do século XIX, professores do século XX e alunos do século XXI?: a subjetivação no discurso sobre a educação escolar. 2016. 120 f. Dissertação (Mestrado em Letras) - Programa de Pós-Graduação em Letras, Universidade Federal do Amazonas, Manaus, 2016. Disponível em: https://tede.ufam.edu.br/handle/tede/5337. Acesso em: 30 out. 2020.

RAMBO, L. I. Prefácio. In: PALÚ, J.; SCHUTZ, J. A.; MAYER, L. (Org.). Desafios da educação em tempos de pandemia. Cruz Alta: Ilustração, 2020.

RANGEL, M. Supervisão pedagógica: princípios e práticas. 12. ed. Campinas, SP: Papirus, 2011.

RIO DE JANEIRO (Estado). Decreto no 46.970, de 13 de março de 2020. Dispõe sobre medidas temporárias de prevenção ao contágio e de enfrentamento da propagação decorrente do novo coronavírus (COVID-19), do regime de trabalho de servidor público e contratado, e dá outras providências. Diário Oficial do Estado do Rio de Janeiro, Rio de Janeiro, 13 mar. 2020a. Disponível em: https://pge.rj.gov.br/comum/code/MostrarArquivo.php?C=MTAyMjE\%2C. Acesso em: 31 out. 2020.

RIO DE JANEIRO. Secretaria Estadual de Educação. Resolução SEEDUC no 5.839, de 16 de março de 2020. Regulamenta o Decreto no 46.970, de 13 de março de 2020, que trata sobre medidas temporárias de prevenção ao contágio e de enfrentamento da propagação decorrente do novo coronavírus (COVID-19), estabelece alteração do calendário escolar para o 


\section{RevistAleph}

ano letivo de 2020, funcionamento das unidades escolares, diretorias regionais e sede SEEDUC, e promove recomendações para prevenção e controle de infecções a serem adotadas nas unidades socioeducativas do estado do Rio de Janeiro. Diário Oficial do Estado do Rio de Janeiro, Rio de Janeiro, 17 mar 2020b. Disponível em: https://rj.undime.org.br/uploads/documentos/phpliJZCJ_5e73bd6f4c98a.pdf. Acesso em: 31 out. 2020.

SILVA, M. Formação de professores para a docência online. In: Congresso Internacional Galego-Português de Psicopedagogia, 10, 2009, Braga. Atas [...]. Braga: Universidade do Minho, 2009. p. 25-40. Disponível em:

https://www.educacion.udc.es/grupos/gipdae/documentos/congreso/Xcongreso/pdfs/cc/cc2. pdf

SILVA, M. Educar na cibercultura: desafios à formação de professores para docência em cursos online. Revista Digital de Tecnologias Cognitivas, São Paulo, n. 3, p. 36-51, jan./jun. 2010. Disponível em: https://www4.pucsp.br/pos/tidd/teccogs/artigos/2010/edicao_3/3educar_na_cibercultura-

desafios_formacao_de_professores_para_docencia_em_cursos_online-marco_silva.pdf Acesso em: 20 ago. 2020.

SILVA, Y. O. ; TOSCHI, M. S. Mediação na educação: reflexões na modalidade a distância. Educativa, Goiânia, v. 18, n.1, p. 61-80, jan./jun. 2015. Disponível em: http://seer.pucgoias.edu.br/index.php/educativa/article/viewFile/4256/2446. Acesso em: 20 ago. 2020.

THOMPSON, E. P. A formação da classe operária inglesa I: a árvore da liberdade. Rio de Janeiro: Paz e Terra, 2004.

THOMPSON, E. P. A formação da classe operária inglesa III: a força dos trabalhadores. Rio de Janeiro: Paz e Terra, 2002.

VALENTE, J. A. O ensino híbrido veio para ficar. In: BACICH, L.; TANZI NETO, A.; TREVISANI, F. de M. (org.) Ensino híbrido: personalização e tecnologia na educação. 1. ed. Porto Alegre: Penso, 2015.

ZUIN, A. A. S. Educação a distância ou educação distante?: o Programa Universidade Aberta do Brasil, o tutor e o professor virtual. Educação \& Sociedade, Campinas, v. 27, n. 96, p. 935-954, out. 2006. Disponível em https://www.scielo.br/scielo.php?pid=S0101-

73302006000300014\&script=sci_abstract\&tlng=pt. Acesso em: 20 ago. 2020.

Data do envio: $31 / 08 / 2020$

Data do aceite: 10/02/2021 